\title{
Decoupling Control Strategy of BLIM considering Rotor Mass Eccentricity
}

\author{
Wenshao Bu $\left(\mathbb{D},{ }^{1}\right.$ Biao $\mathrm{Li}^{2}$, and Chunxiao $\mathrm{Lu}^{2}$ \\ ${ }^{1}$ Electrical Engineering College, Henan University of Science and Technology, Luoyang, 471023, China \\ ${ }^{2}$ Information Engineering College, Henan University of Science and Technology, Luoyang, 471023, China \\ Correspondence should be addressed to Wenshao Bu; wsbu@163.com
}

Received 8 July 2018; Revised 27 September 2018; Accepted 16 October 2018; Published 30 October 2018

Academic Editor: Carlos-Andrés García

Copyright (C) 2018 Wenshao Bu et al. This is an open access article distributed under the Creative Commons Attribution License, which permits unrestricted use, distribution, and reproduction in any medium, provided the original work is properly cited.

\begin{abstract}
A BLIM, i.e., bearingless induction motor, is a multivariable, nonlinear, and strong coupling object; to achieve its high performance magnetic suspension operation control and overcome the influence of the rotor mass eccentricity, a decoupling control strategy considering the rotor mass eccentricity is proposed. Firstly, the mathematical model of the torque system based on the rotor flux orientation and the mathematical model of the magnetic suspension system based on the air gap flux orientation are presented; on this basis, the inverse system decoupling control method of the BLIM is researched. Then, according to the frequency characteristics of the unbalanced displacement, an unbalance vibration compensator is designed, which can generate a compensation force to suppress or eliminate the unbalanced displacement. Simulation experimental results have shown that the decoupling control among the rotor flux-linkage, motor speed, and two radial displacement components can be achieved; in the steady state, the unbalanced displacement can be basically eliminated, while, during the mutation process of motor speed, the unbalanced displacement can be suppressed effectively.
\end{abstract}

\section{Introduction}

The motor supported by the mechanical bearings cannot meet the need of high-speed and long-time operation $[1,2]$. Then the motor supported by the magnetic bearing is widely developed $[3,4]$, but it still has some disadvantages, such as the more power consumption for magnetic suspension and the overspeed difficulty [5]. The bearingless motor is a new type of AC motor, which is proposed based on the structure similarity between the magnetic bearing and the common $\mathrm{AC}$ motor stator $[3,4]$. In the common bearingless motor, there are two sets of stator windings, i.e., torque windings (pole-pair number $p_{1}$, angle frequency $\omega_{1}$ of current) and suspended windings (pole-pair number $p_{2}$, angle frequency $\omega_{2}$ of current). When the two sets of stator windings meet the qualifications of " $p_{1}=p_{2} \pm 1$ " and " $\omega_{1}=\omega_{2}$," a stable and controllable magnetic suspension force can be generated. Figure 1 shows the schematic diagram of the generation principle of the controllable magnetic suspension force [6]. The bearingless motor has a series of advantages, such as no friction, no mechanical noise, and higher critical speed; then it is more suitable for high-speed operation, and it has become a research hotspot [5-12].

The bearingless induction motor (BLIM) is a multivariable, nonlinear, and strong coupling object. To realize its high performance control, it is necessary to achieve the dynamic decoupling between the controlled variables. As for a nonlinear system, the inverse system method is an effective one that can be used for the liberalization decoupling $[12,13]$. In addition, to improve the control performance of the torque system, the rotor flux orientation is usually adopted. About the inverse system decoupling control strategy of the BLIM based on the rotor flux orientation, there has been some research progress [13-15]. But for the magnetic suspension system, the air gap flux-linkage of the torque system is required in the model of magnetic suspension force. In the coordinate system orientated by the rotor flux-linkage of the torque system, the air gap flux-linkage components of the torque system are time-varying, which will inevitably lead to the calculation complexity of the suspension control current. 


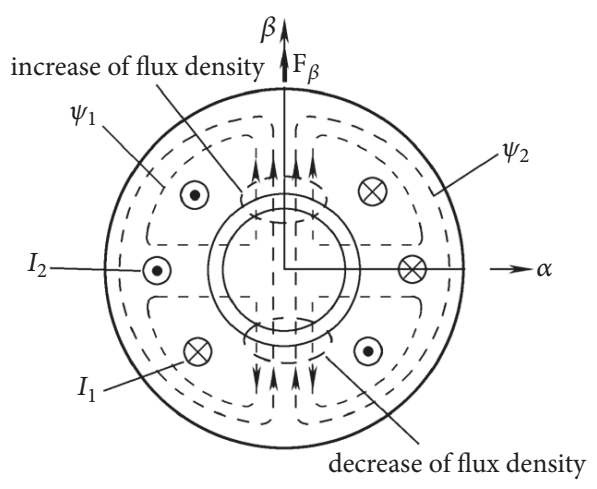

FIGURE 1: Schematic diagram of controllable magnetic suspension force generation.

In this paper, the rotor flux orientation is still applied to the torque system; but in the magnetic suspension system, the magnetic suspension force will be controlled based on the synthetic air gap flux-linkage of the torque system; the inverse system decoupling will be applied to the overall BLIM system; the required air gap flux-linkage of the torque system will be obtained by an independent air gap flux-linkage observer.

In addition, due to the uneven material, machining accuracy, assembly error, and other reasons, the mass eccentricity of rotor is unavoidable, and, during the rotor rotation, an unbalanced excitation force acting on the rotor is generated. The unbalanced excitation force has the same angle frequency with the rotational speed, which will lead to the unbalance vibration [16-19]. In view of the uncertainties of the mass eccentric direction and the mass eccentricity, it is difficult to establish an accurate model of unbalanced excitation force, and then it is difficult to solve the unbalance vibration problem by an analytic inverse system method. But the unbalanced excitation force will generate an unbalanced displacement. In this paper, the radial displacement would be divided into two parts, i.e., the random displacement and the unbalanced displacement; the inverse system decoupling control strategy is adopted to control the random displacement, and a vibration compensation controller is adopted to suppress or eliminate the unbalanced displacement. Simulation experimental results have shown that the decoupling control between the motor speed, rotor flux-linkage, and two radial displacement components can be realized; the unbalanced displacement can be effectively suppressed.

\section{Mathematical Model of BLIM}

\subsection{Model of Torque System}

Definition. $d-q$ is the rotor flux orientation coordinate system of the torque system. Then in the $d$-q coordinate system, the motion equation and the rotor flux-linkage equation can be expressed as follows:

$$
\dot{\omega}_{r}=\frac{p_{1} L_{m 1}}{J L_{r}} \psi_{r} i_{s 1 q}-\frac{1}{J} T_{L}
$$

$$
\begin{aligned}
& \dot{\psi}_{r}=-\frac{1}{T_{r}} \psi_{r}+\frac{L_{m 1}}{T_{r}} i_{s 1 d} \\
& \theta_{1}=\int\left(p_{1} \omega_{r}+\omega_{s}\right)=\int\left(p_{1} \omega_{r}+\frac{L_{m 1}}{T_{r 1} \psi_{r 1}} i_{s 1 q}\right),
\end{aligned}
$$

where $\omega_{\mathrm{r}}$ is the mechanical angular velocity of rotor; $\omega_{1}$ is the electrical angular velocity of the $d$ - $q$ coordinate system; $\psi_{\mathrm{r}}$ and $\theta_{1}$ are the amplitude and space position angle of the rotor flux-linkage vector; $i_{\text {s1d }}$ and $i_{\text {s1q }}$ are the current components of torque windings along the $d$ - and $q$-coordinate axes; $L_{\mathrm{m} 1}$ is the equivalent two-phase mutual inductance of the torque system; $T_{r}$ is the rotor time constant; $T_{r}=L_{r} / R_{r} ; L_{r}$ is the rotor's self-inductance and $R_{r}$ is the rotor resistance; $J$ is the inertia moment; $p_{1}$ is the pole-pair number of torque windings; $T_{L}$ is the load torque.

2.2. Model of Magnetic Suspension System. The controllable magnetic suspension force acting on the rotor is the interaction result between the air gap flux-linkage of the torque system and that of the magnetic suspension system. In the decoupling calculation of the magnetic suspension system, the air gap flux-linkage information of the torque system is required. Defining $\alpha-\beta$ as the two-phase stationary orthogonal coordinate system, its coordinate origin locates at the center of stator. Then the air gap flux-linkage components of the torque system in the $\alpha$ and $\beta$ direction, i.e., $\psi_{1 \alpha}$ and $\psi_{1 \beta}$, can be expressed as follows:

$$
\begin{aligned}
& \psi_{1 \alpha}=\int\left(u_{s 1 \alpha}-R_{s 1} i_{s 1 \alpha}\right) d t-L_{s 1 l} i_{s 1 \alpha} \\
& \psi_{1 \beta}=\int\left(u_{s 1 \beta}-R_{s 1} i_{s 1 \beta}\right) d t-L_{s 1 l} i_{s 1 \beta},
\end{aligned}
$$

where $u_{\text {s1 } \alpha}$ and $u_{s 1 \beta}$ are the voltage components of torque windings along the $\alpha$ - and $\beta$-coordinate axes; $i_{\text {s1 } \alpha}$ and $i_{\mathrm{s} 1 \beta}$ are the current components of torque windings along the $\alpha$ and $\beta$-coordinate axes; $R_{s 1}$ is the stator resistance of torque windings; $L_{s 1 l}$ is the leakage inductance of torque windings.

Definition. $M-T$ is the air gap flux orientation coordinate system of the torque system. Then the amplitude $\psi_{1 \mathrm{~m}}$ and space position angle $\theta_{2}$ of the air gap flux-linkage of the torque system can be expressed as follows:

$$
\begin{aligned}
\psi_{1 m} & =\sqrt{\psi_{1 \alpha}^{2}+\psi_{1 \beta}^{2}} \\
\theta_{2} & =\arccos \left(\frac{\psi_{1 \alpha}}{\psi_{1 m}}\right) .
\end{aligned}
$$

According to the air gap flux-linkage amplitude of the torque system, the controllable magnetic suspension force components in the static $\alpha$ - $\beta$ coordinate system can be controlled by the suspension current components $i_{\mathrm{s} 2 \mathrm{~m}}$ and $i_{\text {s2t }}$; the specific models can be expressed as follows [18]:

$$
\begin{aligned}
& F_{\alpha}=K_{m} \psi_{1 m} \cdot i_{s 2 m} \\
& F_{\beta}=-K_{m} \psi_{1 m} \cdot i_{s 2 t},
\end{aligned}
$$

where $F_{\alpha}$ and $F_{\beta}$ are the controllable magnetic suspension force components along the $\alpha$ - and $\beta$-coordinate axes; $K_{\mathrm{m}}$ 


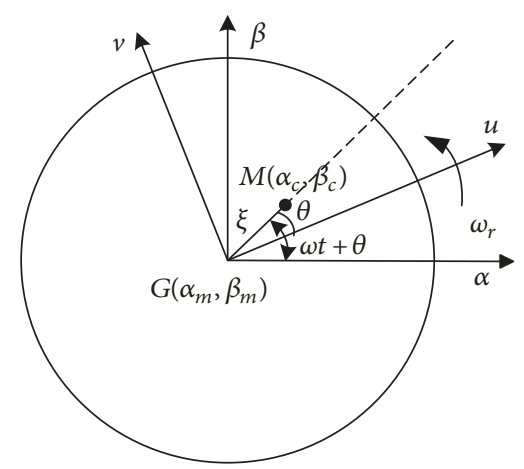

FIGURE 2: Diagram of rotor mass eccentricity.

is the magnetic suspension force coefficient determined by the BLIM structure; $i_{\mathrm{s} 2 \mathrm{~m}}$ and $i_{\mathrm{s} 2 \mathrm{t}}$ are the control current components of magnetic suspension force along the $M$ - and $T$-coordinate axes.

When the rotor deviates from the stator axis, the unilateral electromagnetic pull will be generated, and the specific expressions are as follows:

$$
\begin{aligned}
& f_{s \alpha}=k_{s} \alpha, \\
& f_{s \beta}=k_{s} \beta,
\end{aligned}
$$

where $\alpha$ and $\beta$ are radial displacement components; $k_{\mathrm{s}}$ is the radial displacement stiffness coefficient; $f_{\mathrm{s} \alpha}$ and $f_{\mathrm{s} \beta}$ are the unilateral electromagnetic pull components along the $\alpha$ and $\beta$-coordinate axes, respectively.

Figure 2 presents the rotor mass eccentricity diagram. In Figure $2, u-v$ is the rotor synchronous rotating coordinate system; $M$ is the centroid of rotor; $G\left(\alpha_{\mathrm{m}}, \beta_{\mathrm{m}}\right)$ is the axis of rotor; $\xi$ is the eccentric distance of rotor mass, $\theta$ is the initial mass eccentricity angle in the $u-v$ coordinate system.

During the rotation of the mass eccentric rotor, an unbalanced excitation force $F_{a}$ is generated in the mass eccentricity direction, whose angular frequency is the same with the angular velocity of rotor. The unbalanced excitation force components along the $\alpha$ - and $\beta$-coordinate axes can be expressed as follows [20]:

$$
\begin{aligned}
& F_{\mathrm{a} \alpha}=m \xi \omega^{2} \cos \left(\omega_{r} t+\theta\right) \\
& F_{\mathrm{a} \beta}=m \xi \omega^{2} \sin \left(\omega_{r} t+\theta\right),
\end{aligned}
$$

where $m$ is the rotor mass.

The rotor's radial suspension motion equation can be expressed as follows:

$$
\begin{aligned}
& m \ddot{\alpha}=F_{\alpha}+F_{\mathrm{a} \alpha}+f_{s \alpha} \\
& m \ddot{\beta}=F_{\beta}+F_{\mathrm{a} \beta}+f_{s \beta} .
\end{aligned}
$$

\section{Control System of BLIM}

The decoupling control based on the inverse system method requires the analytical model of the BLIM system. But it is difficult to measure the eccentric distance $\xi$ and the initial eccentricity angle $\theta$ of rotor mass. But the research results show that the unbalanced excitation force will generate periodic unbalanced displacement, and it has no effect on the random displacement $[12,13]$. The unbalanced displacement components along the $\alpha$ - and $\beta$-coordinate axes are sine and cosine signals, respectively, whose frequencies are the same with the angular velocity of rotor, and they can be expressed as follows:

$$
\begin{aligned}
& \alpha_{m}=A \cos \left(\omega_{r} t+\varphi\right) \\
& \beta_{m}=A \sin \left(\omega_{r} t+\varphi\right),
\end{aligned}
$$

where " $A$ " is the amplitude of unbalanced displacement, and it is proportional to the square of motor speed; $\varphi$ is the initial phase angle of unbalanced displacement.

In this paper, the radial displacement is divided into a random displacement component and an unbalanced displacement component. Then by the vibration compensation controller, a vibration compensation force is generated, which is used to suppress or eliminate the unbalanced displacement. As for the random displacement, an inverse system decoupling control strategy is adopted.

3.1. Inverse System Decoupling Control. Select the system state variable $x$, input variable $u$, and output variables $y$ as follows:

$$
\begin{aligned}
& x=\left(x_{1}, x_{2}, x_{3}, x_{4}, x_{5}, x_{6}\right)^{T}=\left(\psi_{r 1}, \omega, \alpha, \beta, \dot{\alpha}, \dot{\beta}\right)^{T} \\
& u=\left(u_{1}, u_{2}, u_{3}, u_{4}\right)^{T}=\left(i_{s 1 d}, i_{s 1 q}, i_{s 2 m}, i_{s 2 t}\right)^{T} \\
& y=\left(y_{1}, y_{2}, y_{3}, y_{4}\right)^{T}=\left(\psi_{r 1}, \omega, \alpha, \beta\right)^{T} .
\end{aligned}
$$

Substituting (12), (13), and (14) into (1), (2), and (10), then the state equations of the BLIM system can be derived as follows:

$$
\begin{aligned}
& \dot{x}_{1}=-\frac{x_{1}}{T_{r 1}}+\frac{L_{m 1} u_{1}}{T_{r 1}} \\
& \dot{x}_{2}=\frac{p_{1} L_{m 1} x_{1} u_{2}}{\left(J L_{r 1}\right)}-\frac{T_{L}}{J} \\
& \dot{x}_{3}=x_{5} \\
& \dot{x}_{4}=x_{6} \\
& \dot{x}_{5}=\frac{K_{m} \psi_{1 m} u_{3}}{m}+\frac{k_{s} x_{3}}{m} \\
& \dot{x}_{6}=-\frac{K_{m} \psi_{1 m} u_{4}}{m}+\frac{k_{s} x_{4}}{m} .
\end{aligned}
$$

where the rotor flux orientation is adopted for the torque system; based on the air gap flux-linkage of the torque system, the magnetic suspension force and the radial suspension motion of the rotor are controlled by the control current components of the magnetic suspension system, and the required air gap flux-linkage information is obtained in real time from $(4) \sim(6)$. 
In order to analyze the reversibility of the BLIM system, according to the Interactor algorithm, each output variable $y_{i}(i=1,2,3,4)$ is asked derivative to time, until the input variables are included in the derivative expression. The specific processes can be expressed as follows:

$$
\begin{aligned}
& \dot{y}_{1}=\dot{x}_{1}=-\frac{x_{1}}{T_{r 1}}+\frac{L_{m 1} u_{1}}{T_{r 1}} \\
& \dot{y}_{2}=\dot{x}_{2}=\frac{p_{1} L_{m 1} x_{1} u_{2}}{\left(J L_{r 1}\right)}-\frac{T_{L}}{J} \\
& \dot{y}_{3}=\dot{x}_{3}=x_{5} \\
& \ddot{y}_{3}=\dot{x}_{5}=\frac{K_{m} \psi_{1 m} u_{3}}{m}+\frac{k_{s} x_{3}}{m} \\
& \dot{y}_{4}=\dot{x}_{4}=x_{6} \\
& \ddot{y}_{4}=\dot{x}_{6}=-\frac{K_{m} \psi_{1 m} u_{4}}{m}+\frac{k_{s} x_{4}}{m} .
\end{aligned}
$$

Setting

$$
Y(u)=\left(\dot{y}_{1}, \dot{y}_{2}, \ddot{y}_{3}, \ddot{y}_{4}\right)^{T}
$$

then the Jacobi matrix of the BLIM system can be derived as follows:

$$
\begin{aligned}
A(x, u) & =\frac{\partial Y}{\partial u^{T}} \\
& =\left(\begin{array}{cccc}
\frac{L_{m 1}}{T_{r 1}} & 0 & 0 & 0 \\
0 & \frac{p_{1} L_{m 1} x_{1}}{J L_{r 1}} & 0 & 0 \\
0 & 0 & \frac{K_{m} \psi_{1 m}}{m} & 0 \\
0 & 0 & 0 & -\frac{K_{m} \psi_{1 m}}{m}
\end{array}\right) .
\end{aligned}
$$

In the normal operation of the BLIM system, $x_{1}=\psi_{r} \neq 0$, $\psi_{1 m} \neq 0$. Then $\operatorname{rank}[A(x, u)]=4$, and $A(x, u)$ is nonsingular. The relative order $\alpha=\left(\alpha_{1}, \alpha_{2}, \alpha_{3}, \alpha_{4}\right)=(1,1,2,2)$, while $\sum \alpha_{i}=$ $6=n(i=1,2,3,4)$. And then the BLIM system is reversible.

Select the input of inverse system as follows:

$$
v=\left(\dot{y}_{1}, \dot{y}_{2}, \ddot{y}_{3}, \ddot{y}_{4}\right)^{T}=\left(v_{1}, v_{2}, v_{3}, v_{4}\right)^{T} \text {. }
$$

Substituting (22) into (16) (19), then the inverse system model of the BLIM can be derived as follows:

$$
\begin{aligned}
& u_{1}=\frac{T_{r 1}}{L_{m 1}} v_{1}+\frac{1}{L_{m 1}} x_{1}, \\
& u_{2}=\frac{L_{r 1}}{p_{1} L_{m 1} x_{1}}\left(J v_{2}+T_{L}\right) \\
& u_{3}=\frac{\left(m v_{3}-k_{s} x_{3}\right)}{K_{m} \psi_{1 m}}, \\
& u_{4}=-\frac{\left(m v_{4}-k_{s} x_{4}\right)}{K_{m} \psi_{1 m}} .
\end{aligned}
$$

From (23) and (24), it can be seen that when the magnetic suspension system is controlled based on the air gap fluxlinkage of the torque system, it only needs to calculate the air gap flux-linkage of the torque system in real time; in addition, there is no obvious coupling between the inverse model of the torque system and that of the magnetic suspension system; this facilitates the "independent inverse system decoupling" between the torque system and the suspension system.

By connecting the inverse system in series before the original BLIM system, the torque system is dynamically decoupled into two first-order linear integral subsystems, including a rotor flux-linkage subsystem and a motor speed subsystem; meanwhile the magnetic suspension system is dynamically decoupled into two second-order linear integral subsystems, including the $\alpha$ random displacement component subsystem and the $\beta$ random displacement component subsystem. Then by adding an appropriate regulator for each subsystem, the dynamic decoupling control among the rotor flux-linkage, motor speed, and $\alpha$ and $\beta$ random displacement components can be realized.

3.2. Compensation Control of Unbalance Vibration. The radial displacement components caused by the mass eccentricity along the $\alpha$ - and $\beta$-coordinate axes are sine and cosine signals, whose frequencies are the same with the angular speed of rotor. From these characteristics, the extraction of unbalanced displacement and the compensation of unbalanced excitation force can be realized. The processes can be summed up as follows: Firstly, define $u-v$ as the synchronous coordinate system rotating with the rotor. From the rotor synchronous rotation transformation, the radial displacement components measured in the $\alpha-\beta$ coordinate system are transformed to those in the $u-v$ coordinate system. Then in the $u-v$ coordinate system, the DC variable signals of unbalanced displacement, i.e., $u_{m}$ and $v_{m}$, are extracted by relevant low pass filters. Secondly, in the $u-v$ coordinate system, the given signals of unbalanced displacement components are set to zero; then through the closed-loop controls of $u_{m}$ and $v_{m}$, the given signals of vibration compensation force components in the $u-v$ coordinate system, i.e., $F_{\mathrm{cu}}{ }^{*}$ and $F_{\mathrm{cv}}{ }^{*}$, are obtained. Thirdly, through the reverse rotating transformation for $F_{\mathrm{cu}}{ }^{*}$ and $F_{\mathrm{cv}}{ }^{*}$, the given signals of vibration compensation force components in the $\alpha-\beta$ coordinate system, i.e., $F_{c \alpha}{ }^{*}$ and $F_{c \beta}{ }^{*}$, are obtained.

Figure 3 shows the schematic diagram of unbalance vibration compensation controller, where $\alpha$ and $\beta$ are the measured radial displacements; $u_{m}$ and $v_{m}$ are the unbalanced displacement components in the $u-v$ coordinate system; $F_{c u}{ }^{*}$ and $F_{c v}{ }^{*}$ are the vibration compensation force DC signals in the $u-v$ coordinate system; $F_{\mathrm{ca}}{ }^{*}$ and $F_{\mathrm{c} \beta}{ }^{*}$ are the vibration compensation force AC signals in the $\alpha-\beta$ coordinate system.

Because the output variables of the BLIM inverse system are current signals, the "force/current" transformation is needed to convert the vibration compensation force to the vibration compensation current. After the vibration compensation current is superposed on the control current of random displacement, the integrated control for the random and unbalanced displacements can be realized. 


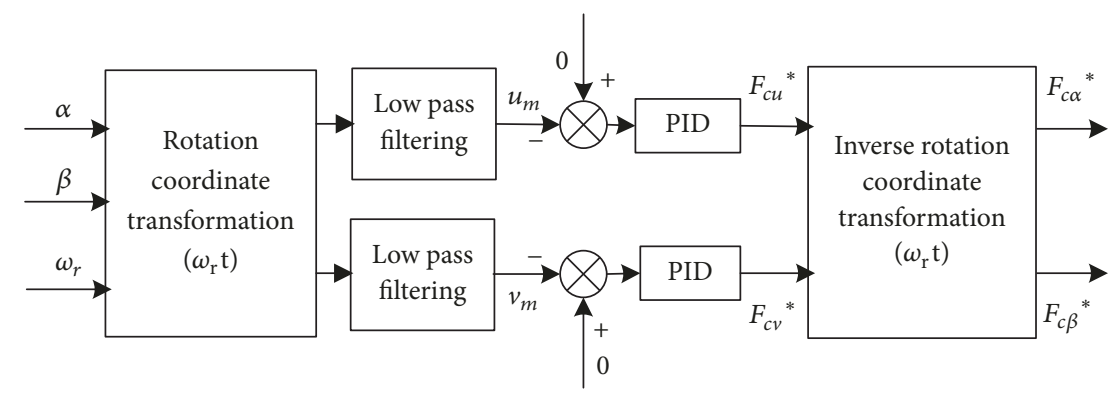

FIGURE 3: Unbalance vibration compensation controller.

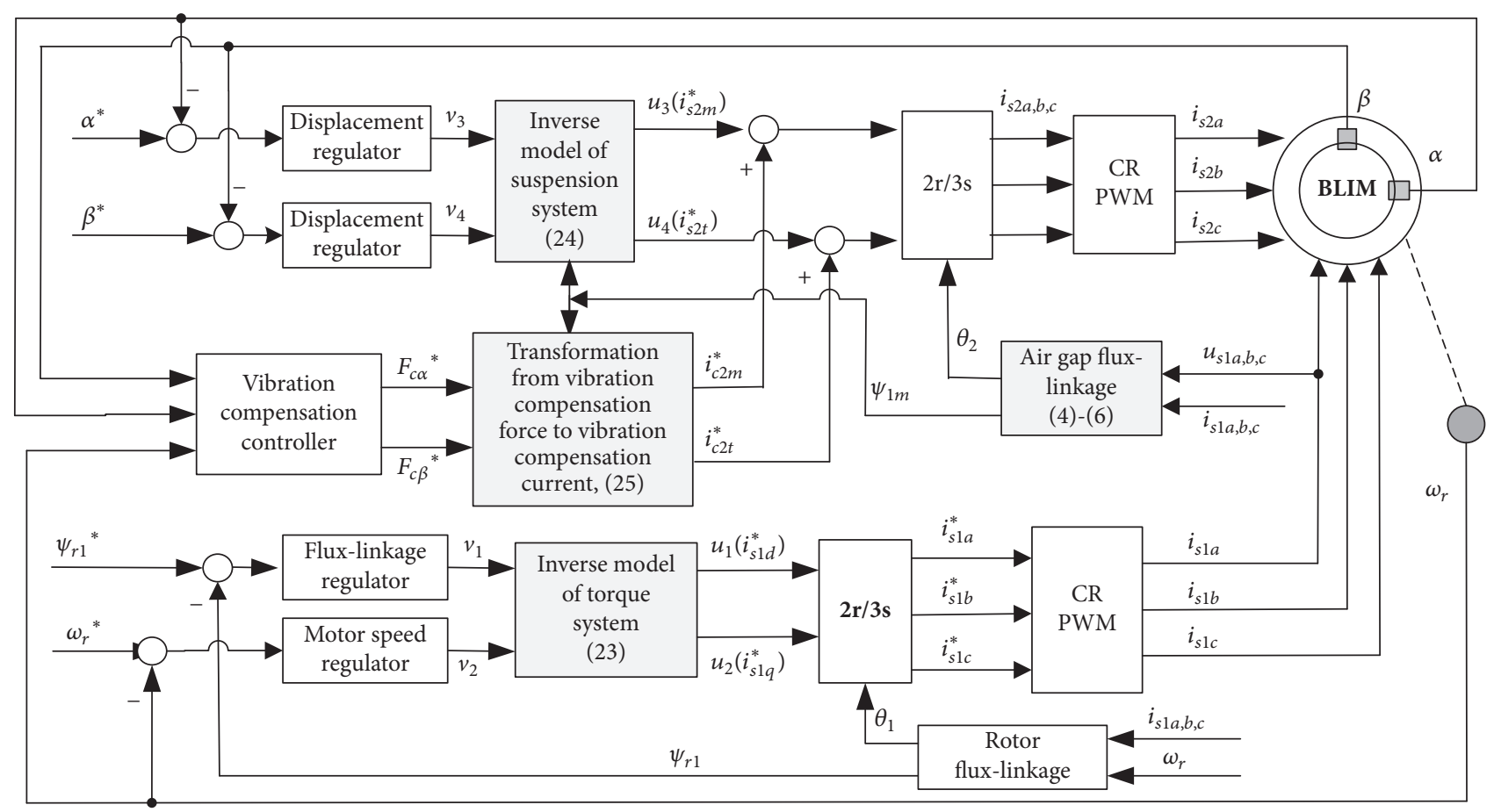

FIGURE 4: Unbalance vibration control system of bearingless induction motor.

Replacing $F_{\alpha}$ and $F_{\beta}$ in (7) with $F_{c \alpha}{ }^{*}$ and $F_{c \beta}{ }^{*}$, then the analytical formula of vibration compensation current can be derived as follows:

$$
\begin{aligned}
& i_{c 2 m}^{*}=\frac{F_{c \alpha}^{*}}{K_{m} \psi_{1 m}}, \\
& i_{c 2 t}^{*}=-\frac{F_{c \beta}^{*}}{K_{m} \psi_{1 m}} .
\end{aligned}
$$

In (25), $i^{*}{ }_{\mathrm{c} 2 \mathrm{~m}}$ and $i^{*}{ }_{\mathrm{c} 2 \mathrm{t}}$ are the given signals of the vibration compensation current components along the $\mathrm{m}$ and t-coordinate axes.

Figure 4 is the schematic diagram of the unbalance vibration compensation control system.

\section{Simulation Verification of BLIM Control System}

4.1. Decoupling Control Performance of BLIM System. According to Figure 4, a four-pole BLIM with twopole suspension windings is taken as the object; system simulation is carried out by Matlab/Simulink. In order to verify the decoupling performance between the motor speed, rotor flux-linkage, and two displacement components, the influence of rotor unbalance vibration is temporarily ignored; the given values of related variables are suddenly changed at different times: the given rotor flux-linkage is reduced from $0.95 \mathrm{~Wb}$ to $0.5 \mathrm{~Wb}$ at $0.5 \mathrm{~s}$; the given motor speed is increased to $3000 \mathrm{r} / \mathrm{min}$ from $1500 \mathrm{r} / \mathrm{min}$ at $0.75 \mathrm{~s}$; the given $\alpha$ displacement is increased to $0.03 \mathrm{~mm}$ from 


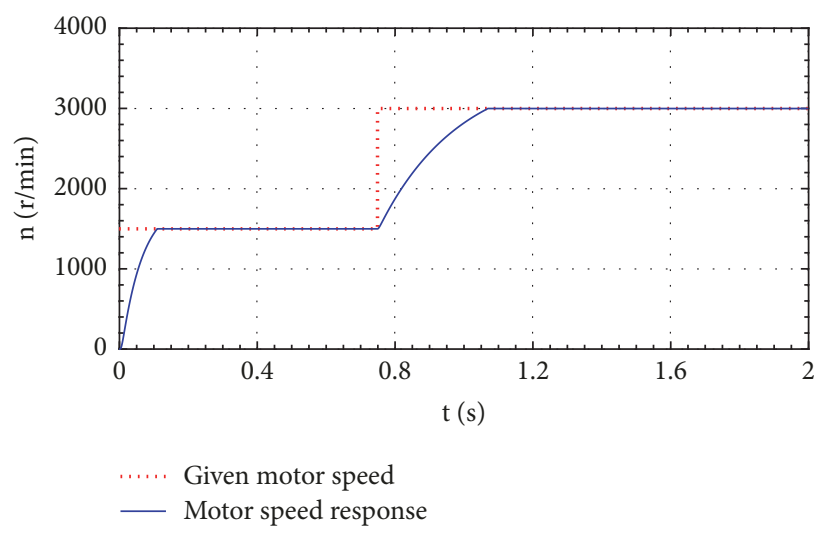

(a) Response curve of motor speed

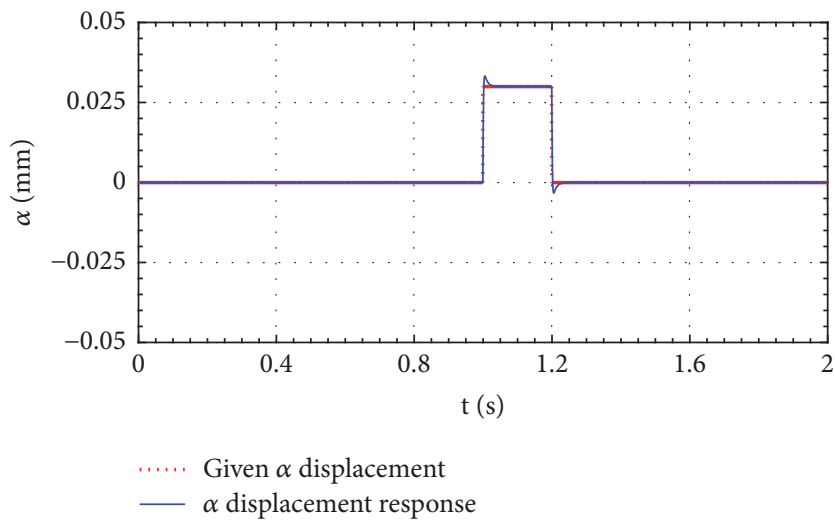

(c) Radial displacement response in $\alpha$ direction

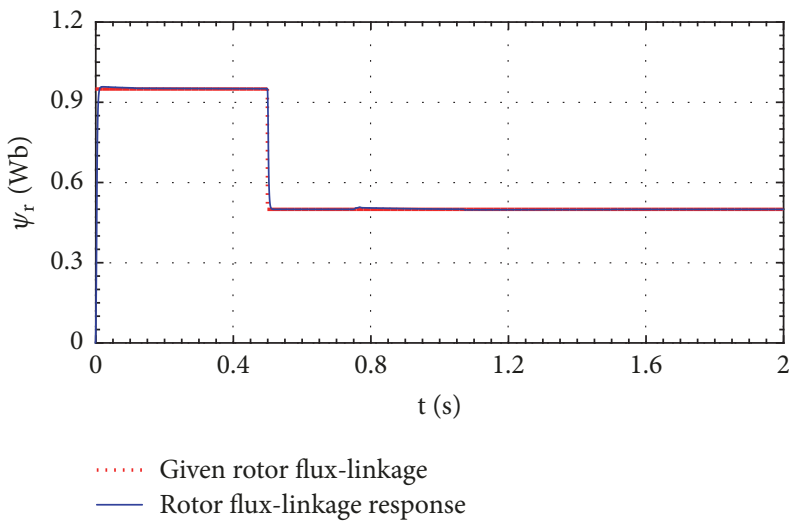

(b) Response curve of rotor flux-linkage

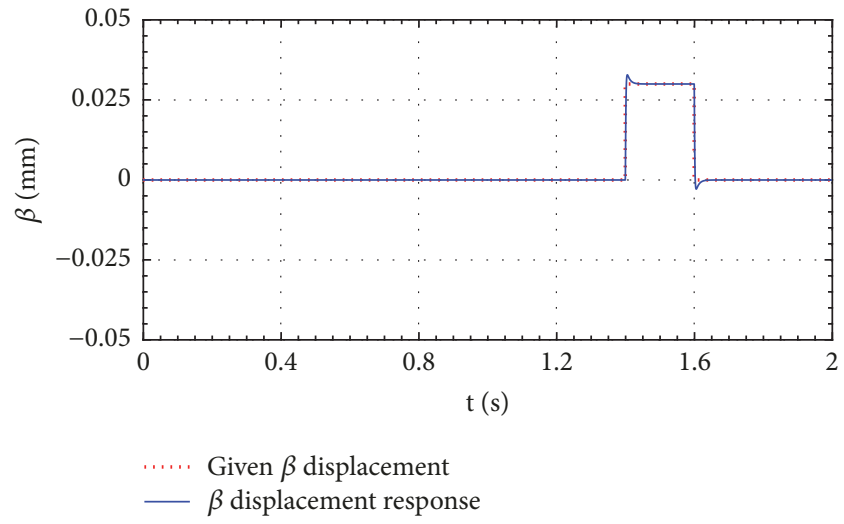

(d) Radial displacement response in $\beta$ direction

FIGURE 5: Response curves of decoupling control system.

$0.0 \mathrm{~mm}$ at $1.0 \mathrm{~s}$ and recovered to $0.0 \mathrm{~mm}$ at $1.2 \mathrm{~s}$; the given $\beta$ displacement is increased to $0.03 \mathrm{~mm}$ from $0.0 \mathrm{~mm}$ at $1.4 \mathrm{~s}$ and recovered to $0.0 \mathrm{~mm}$ at $1.6 \mathrm{~s}$; a 10 N.m load torque is suddenly added at $1.5 \mathrm{~s}$.

Figure 5 shows the response curves of the BLIM control system. From Figure 5, it can be seen that when any one of the motor speed, rotor flux-linkage, and $\alpha$ and $\beta$ radial displacement components is suddenly changed, the other controlled variables basically remain unchanged or vary very little. The simulation results have shown that a good decoupling control between relevant controlled variables is achieved. In addition, the control system has some advantages, such as a faster response speed and a stronger resistance to load.

4.2. Compensation Effect of Unbalance Vibration. Set the following: rotor mass $m=8 \mathrm{~kg}$ and eccentric distance of rotor mass $\xi=0.5 \mathrm{~mm}$, initial displacement $\alpha_{0}=-0.12 \mathrm{~mm}$ and $\beta_{0}=-$ $0.16 \mathrm{~mm}$, given displacement $\alpha^{*}=\beta^{*}=0.0 \mathrm{~mm}$, given rotor flux-linkage $0.95 \mathrm{~Wb}$, and given motor speed $1500 \mathrm{r} / \mathrm{min}$.

Figure 6 shows the displacement response curves before vibration compensation. From Figure 6,

(1) without vibration compensation, under the action of the displacement closed-loop control, the rotor unbalance vibration occurs; the radial displacement components along the $\alpha$ - and $\beta$-coordinate axes present periodic fluctuations

(2) after the BLIM control system enters its steady state, the rotor axis trajectory is a circle with an amplitude of about $6 \mu \mathrm{m}$. The rotor's suspension control precision is greatly influenced

Figure 7 presents the displacement response curves after vibration compensation. From Figure 7,

(1) in the initial starting stage, because the vibration compensation force has not been completely established, there exist some fluctuations with a smaller amplitude in the $\alpha$ - and $\beta$-displacement curves; however, with the establishment of vibration compensation force, the unbalanced displacement is quickly suppressed

(2) after the BLIM control system enters its steady state, under the combined action of the random displacement controller and the vibration compensation controller, the unbalanced displacement components along the $\alpha$ - and $\beta$ coordinate axes gradually decrease to zero; the rotor axis trajectory almost shrinks to the stator center; the suspension control precision of rotor has been greatly improved

Taking the horizontal $\alpha$ direction as an example, Figure 8 shows the comparison curves between the unbalanced excitation force and the vibration compensation force. From Figure 8, 


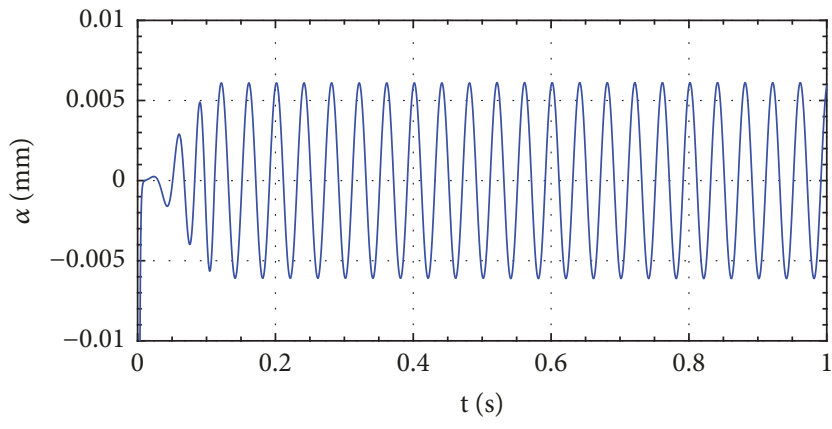

(a) Radial displacement response in $\alpha$ direction

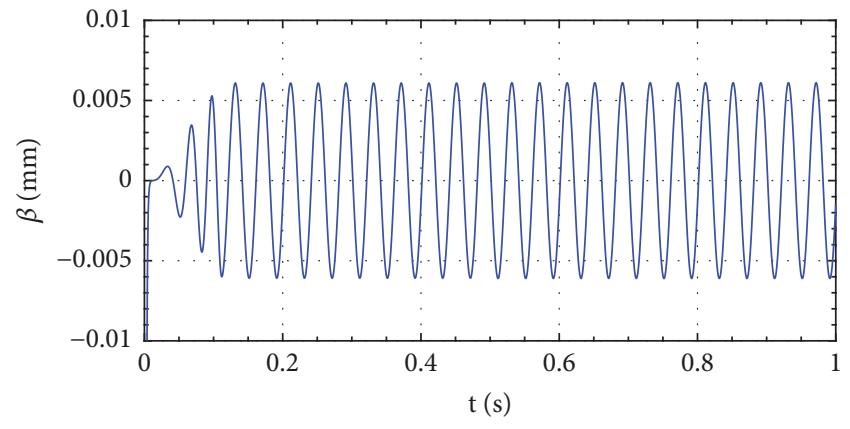

(b) Radial displacement response in $\beta$ direction

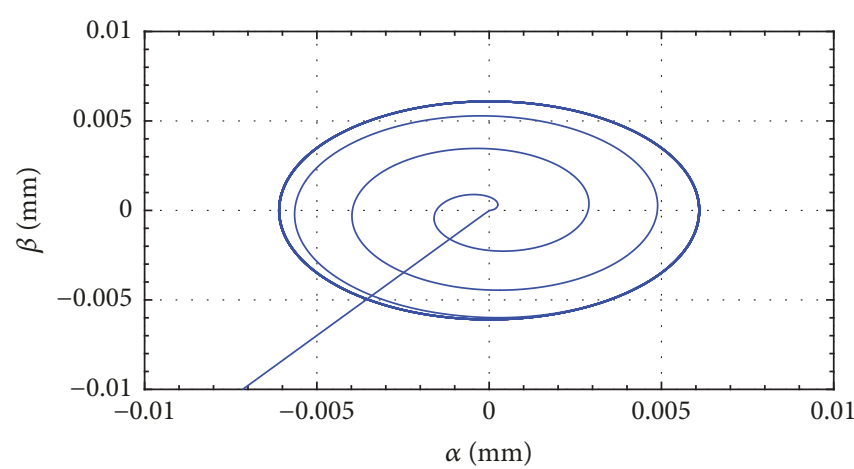

(c) Rotor axis trajectory

FIGURE 6: Displacement curve before vibration compensation.

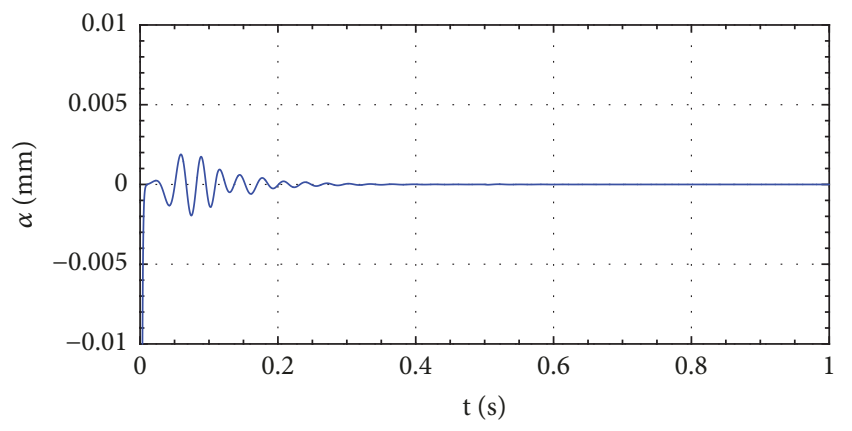

(a) Radial displacement response in $\alpha$ direction

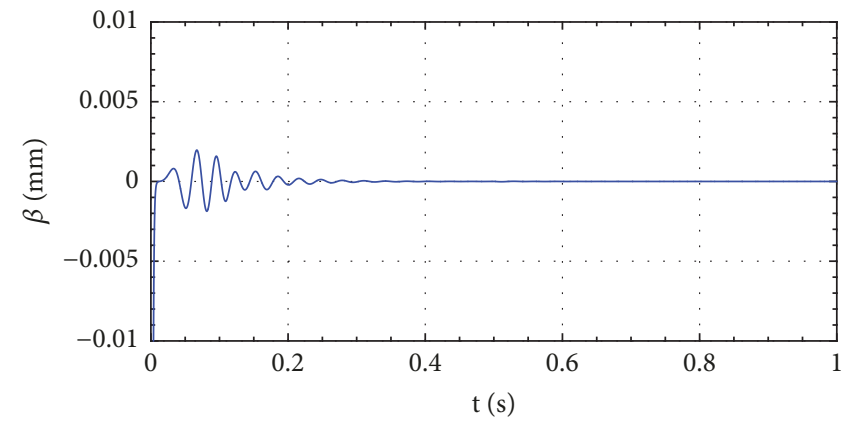

(b) Radial displacement response in $\beta$ direction

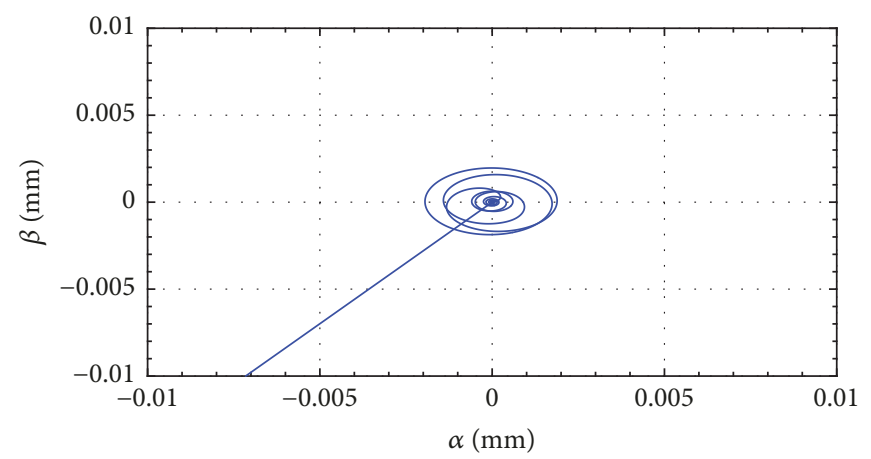

(c) Rotor axis trajectory

FIGURE 7: Displacement curves after vibration compensation. 


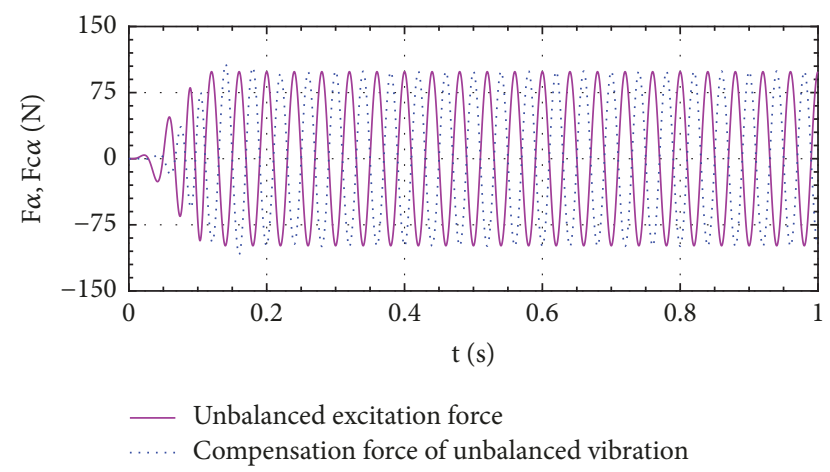

FIGURE 8: Comparison curves between the unbalanced excitation force and the vibration compensation force.

(1) in the initial starting stage, the amplitude of vibration compensation force increases with the unbalanced excitation force

(2) after the BLIM control system enters its steady state, the vibration compensation force is the same as that of the unbalanced excitation force in amplitude, and their direction is always opposite. And then, the vibration compensation force can be used to overcome the influence of the unbalanced excitation force

The comparison curves between the unbalanced excitation force and the vibration compensation force in the vertical $\beta$ direction are similar to that in the horizontal $\alpha$ direction and will not be introduced.

\section{Conclusions}

To solve the strong coupling problem of the BLIM system and to solve the unbalance vibration problem caused by the rotor eccentric mass, a decoupling control strategy of the BLIM system considering the rotor mass eccentricity is studied. In order to achieve a better speed control performance, the rotor flux orientation is adopted for the torque system; to simplify the computational complexity of the magnetic suspension system, the required air gap flux-linkage of the torque system is obtained through independent and realtime calculation, and the rotor suspension motion control is achieved based on the air gap flux-linkage of the torque system. In order to improve the overall dynamic decoupling performance of the BLIM system, the whole inverse system decoupling is adopted. In order to overcome the unbalance vibration problem caused by the rotor mass eccentricity, the compensation controller of unbalance vibration is designed, and the vibration compensation force is used to suppress or eliminate the unbalanced excitation force that acts on the rotor. According to the simulation experimental results, there are the following conclusions:

(1) Adopting the presented control strategy, the dynamic decoupling control between the rotor flux-linkage, motor speed, and two radial displacement components can be achieved

(2) During the change of motor speed, the unbalanced displacement components of rotor can be suppressed effectively; meanwhile in the steady state of the BLIM control system, the unbalanced displacement components can be eliminated, and the magnetic suspension control accuracy of rotor can be greatly improved

\section{Data Availability}

Because the original datasets are captured by our research group, the datasets generated and/or analyzed during the current study are available from the corresponding author on reasonable request.

\section{Conflicts of Interest}

The authors declare that they have no conflicts of interest.

\section{Acknowledgments}

This work is supported by the National Natural Science Foundation of China (51277053).

\section{References}

[1] A. Chiba, T. Fukao, O. Ichikawa et al., Magnetic bearings and bearingless drives, Elsevier Newnes Press, Boston, MA, USA, 2005.

[2] X.-g. Wu and D.-y. Zheng, "Contrastive Study on Torque Distribution of Distributed Drive Electric Vehicle under Different Control Methods," Journal of Control Science and Engineering, vol. 2017, Article ID 2494712, 12 pages, 2017.

[3] X. Sun, L. Chen, H. Jiang, Z. Yang, J. Chen, and W. Zhang, "High-performance control for a bearingless permanentmagnet synchronous motor using neural network inverse scheme plus internal model controllers," IEEE Transactions on Industrial Electronics, vol. 63, no. 6, pp. 3479-3488, 2016.

[4] W. S. Bu, S. H. Huang, and S. M. Wan, "General analytical models of inductance matrices of four-pole bearingless motors with two-pole controlling windings," IEEE Transactions on Magnetics, vol. 45, no. 9, pp. 3316-3321, 2009.

[5] H. Sugimoto, S. Tanaka, and A. Chiba, "A vibration reduction method of one-axis actively position regulated single-drive bearingless motor with repulsive passive magnetic bearings," IEEE Transactions on Industry Applications, vol. 52, no. 1, pp. 181-188, 2016.

[6] W. Bu, C. Lu, C. Zu, H. Zhang, and J. Xiao, "Inverse system decoupling control strategy of BLIM based on stator flux orientation," International Journal of Applied Electromagnetics and Mechanics, vol. 48, no. 4, pp. 469-480, 2015.

[7] H. Wang, J. Bao, B. Xue, and J. Liu, "Control of suspending force in novel permanent-magnet-biased bearingless switched reluctance motor," IEEE Transactions on Industrial Electronics, vol. 62, no. 7, pp. 4298-4306, 2015.

[8] S. H. Kim, J. W. Shin, and K. Ishiyama, "Magnetic bearings and synchronous magnetic axial coupling for the enhancement of the driving performance of magnetic wireless pumps," IEEE Transactions on Magnetics, vol. 50, no. 1, pp. 1-4, 2014.

[9] J. Huang, B. Li, H. Jiang, and M. Kang, "Analysis and control of multiphase permanent-magnet bearingless motor with a single set of half-coiled winding," IEEE Transactions on Industrial Electronics, vol. 61, no. 7, pp. 3137-3145, 2014.

[10] X. Sun, L. Chen, Z. Yang, and H. Zhu, "Speed-sensorless vector control of a bearingless induction motor with artificial neural 
network inverse speed observer," IEEE/ASME Transactions on Mechatronics, vol. 18, no. 4, pp. 1357-1366, 2013.

[11] W.-s. Bu, C.-1. Zu, and C.-x. Lu, "Inverse System Analysis and Modeling of Bearingless Induction Motor and Its Combined Control Strategy," Mathematical Problems in Engineering, vol. 2014, Article ID 698171, 8 pages, 2014.

[12] X. Cao and Z. Deng, "A full-period generating mode for bearingless switched reluctance generators," IEEE Transactions on Applied Superconductivity, vol. 20, no. 3, pp. 1072-1076, 2010.

[13] X. Sun, B. Su, L. Chen, Z. Yang, J. Chen, and W. Zhang, "Nonlinear flux linkage modeling of a bearingless permanent magnet synchronous motor based on AW-LSSVM regression algorithm," International Journal of Applied Electromagnetics and Mechanics, vol. 51, no. 2, pp. 151-159, 2016.

[14] Z. Q. Wang and X. X. Liu, "Nonlinear internal model control for bearingless induction motor based on neural network inversion," Acta Automatica Sinica, vol. 39, no. 4, pp. 433-439, 2013.

[15] W.-S. Bu, C.-L. Zu, and C.-X. Lu, "Decoupling control strategy of bearingless induction motor under the conditions of considering current dynamic characteristics," Kongzhi Lilun Yu Yingyong/Control Theory and Applications, vol. 31, no. 11, pp. 1561-1567, 2014.

[16] A. Bouaziz, S. Bouaziz, T. Hentati, J. Y. Cholley, and M. Haddar, "Vibrations monitoring of high speed spindle with active magnetic bearings in presence of defects," International Journal of Applied Electromagnetics and Mechanics, vol. 49, no. 2, pp. 207-221, 2015.

[17] T. Zhang and H.-Q. Zhu, "Rotor's mass unbalance compensation control in bearingless permanent magnet-type synchronous motors," Proceedings of the Chinese Society of Electrical Engineering, vol. 27, no. 15, pp. 33-37, 2007.

[18] H.-Q. Zhu and X.-H. Hao, "Compensation control of rotor unbalance vibration on bearingless permanent magnet slice motors," Journal of System Simulation, vol. 22, no. 2, pp. 453457, 2010.

[19] W. Bu, F. He, C. Lu, Z. Li, and J. Xiao, "Unbalanced vibration control strategy of bearingless induction motor based on inverse system decoupling," International Journal of Applied Electromagnetics and Mechanics, vol. 51, no. 4, pp. 455-469, 2016.

[20] H. Gao and LX. Xu, "Real-time vibration compensation for active magnetic bearing systems based on LMS algorithm," Journal of Vibration Engineering, vol. 22, no. 6, pp. 583-587, 2009. 


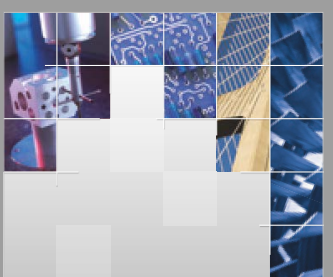

\section{Enfincering}
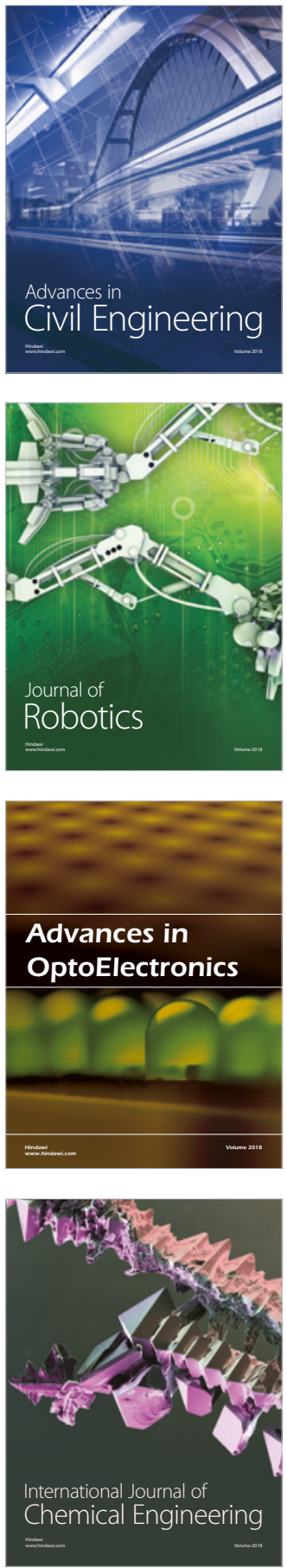

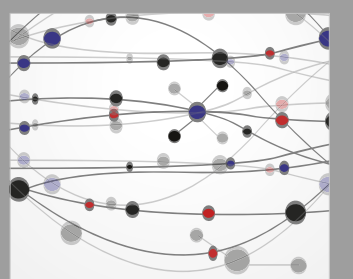

\section{Rotating \\ Machinery}

The Scientific World Journal

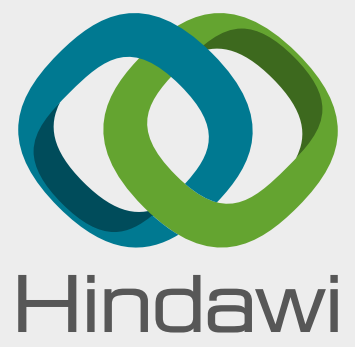

Submit your manuscripts at

www.hindawi.com
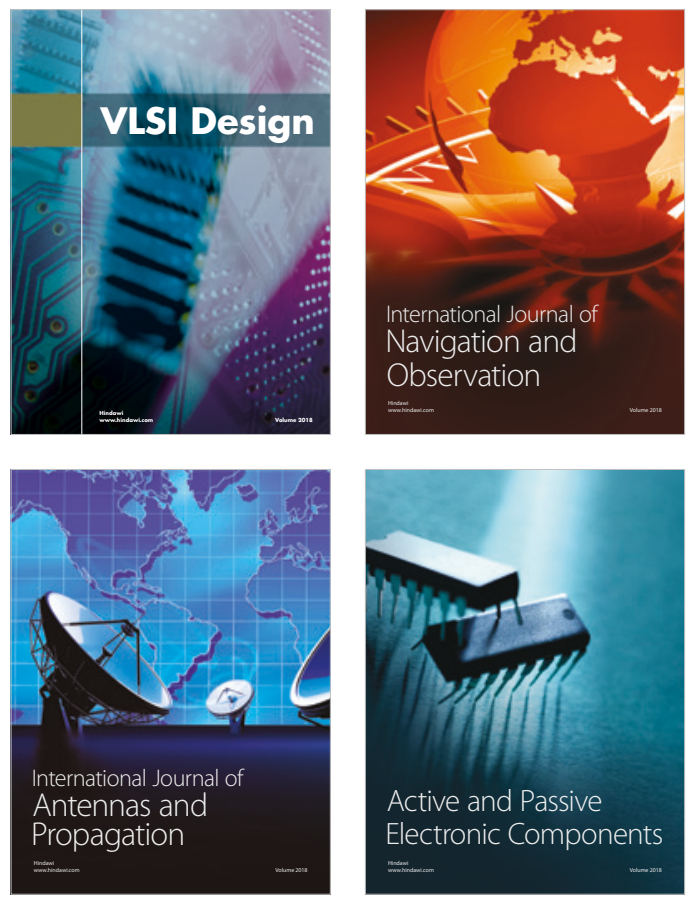
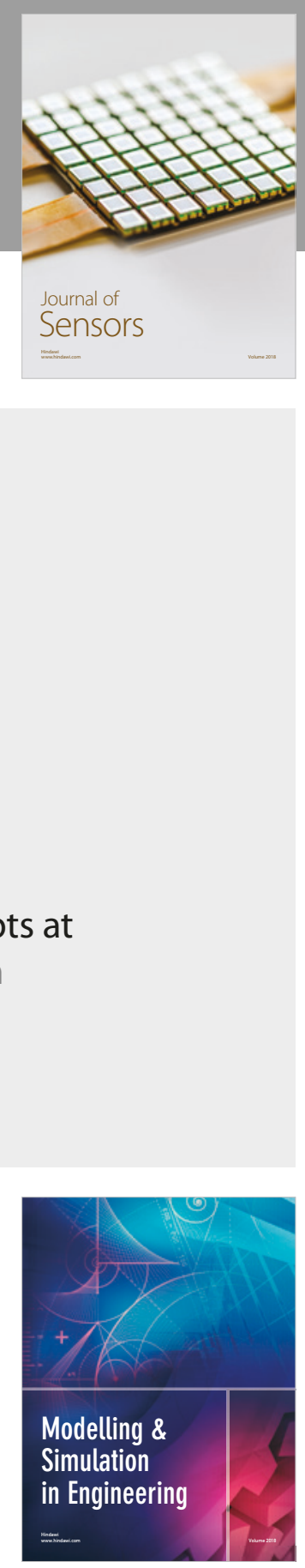

\section{Advances \\ Multimedia}
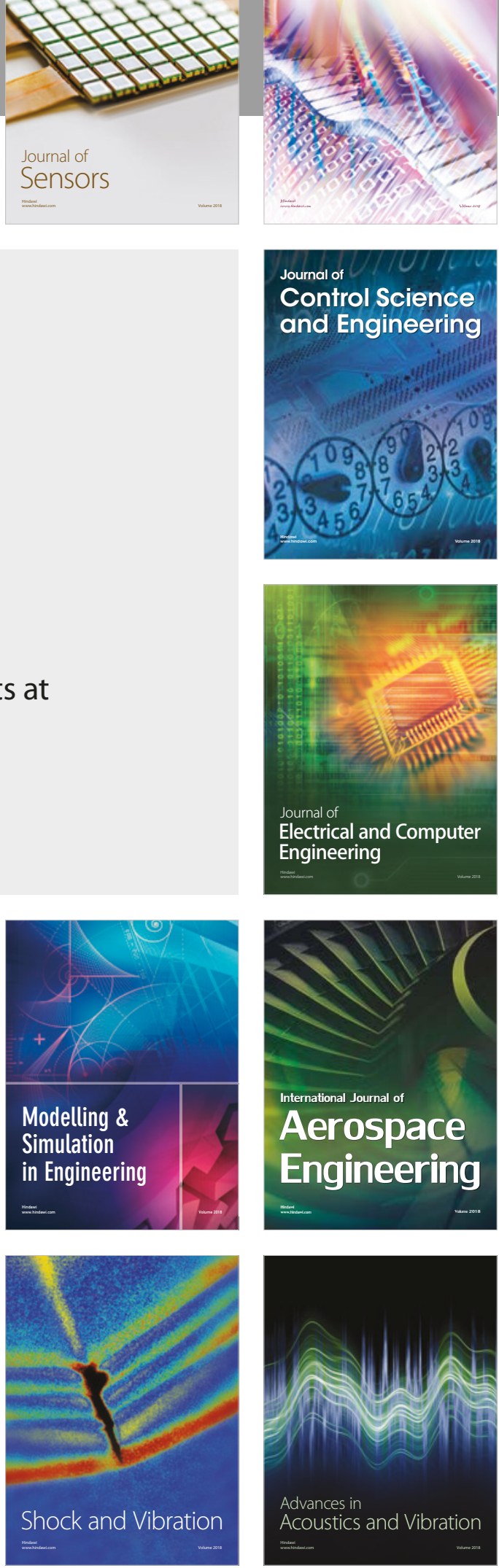